\title{
Oronasopharyngeal chordomas
}

\author{
Jeroen R. Coppens $\cdot$ H. Ric Harnsberger • \\ Michael A. Finn • Pramod Sharma • \\ William T. Couldwell
}

Published online: 26 May 2009

(C) Springer-Verlag 2009

\section{Erratum to: Acta Neurochir \\ DOI 10.1007/s00701-009-0253-1}

Two of the patients in this paper were included in a recent publication in the radiological literature on this subject: Nguyen et al. (2009) Extraosseous chordoma of the nasopharynx. AJNR Am J Neuroradiol. doi:10.3174/ajnr. A1446.

The online version of the original article can be found at http://dx.doi. org/10.1007/s00701-009-0253-1.

J. R. Coppens $\cdot$ M. A. Finn · W. T. Couldwell $(\bowtie)$

Department of Neurosurgery, University of Utah,

Salt Lake, UT 84132, USA

e-mail: neuropub@hsc.utah.edu

J. R. Coppens

e-mail: jeroen.coppens@hsc.utah.edu

M. A. Finn

e-mail: michael.finn@hsc.utah.edu

H. Ric Harnsberger

Department of Radiology, University of Utah,

Salt Lake, UT 84132, USA

e-mail: ric.harnsberger@hsc.utah.edu

P. Sharma

Ear, Nose, and Throat Center,

Salt Lake, UT 84102-1307, USA

e-mail: pramod.sharma@entcenterslc.com 